\title{
CLE \\ In Vitro Studies of 5, 10-Methylenetetrahydrofolate Reductase: Inhibition by Folate Derivatives, Folate Antagonists, and Monoamine Derivatives
}

\author{
*J. L. Hollinger, O. R. Hommes, Th. J.J.M. van de Wiel,
} I. C. N. Kok, and M. I. T. Jansen

*Diaconessentuis, Department of Nearology. Armbem, The Netherlands; and Radboud University Mospital, Department of Newroleggi. Nijmegent. The' Netherlands

\begin{abstract}
Folate monoglutamates and folate antagonists have an inhibitory tion on the activity of 5,10 -methylenetetrahydrofolate reductase in rat brain.

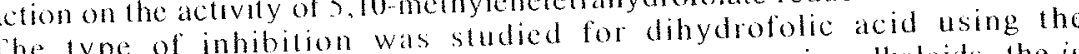
rinewer Burk transformation. Some of the monoamine alkaloids, the in vitu products of 5,10-methylenctertahydrofolate rey Words: 5, 10 stimulatory or inhibitory effect on the enzyme activity. Key Wolate antago Methylenetetrahydrofolate reductase-Folate derivatives-folate antagonists Monoamine derivaltives. Hollinger $\mathbb{J}$. L. et al. In vitro studies of 5,10 methylenetelahydrofolate reductiose: Inhibition by folate derivatives, folate antagonists, and monoamine derivatives. J. Neurochem. 38, 638-642 (1982).
\end{abstract}

The enzyme 5,10-methylenetetrahydrofolate re ductase (EC.1.1.68) catalyzes the reaction:

$$
\begin{gathered}
\text { 5,10-methylene-THF + NADPH + H } \\
\text { 5-methyl-THF + NADP' }
\end{gathered}
$$

This reaction is reversible in the presence of nonspecific electron acceptors (Kutzbach and Stokstad, 1971) (THF = terahydrofolic acid). The 5,10-methylenetetrahydrofolate reduclase is capable of forming 5,10-merhyleneterahydrofolate. which because of an equilibrium reaction yields formaldehyde and tetrahydrofolic acid (Donaldson and Keresztesy, 1961). "In the presence of high concentrations of monoamines, a cyclization of the monoamine with formaldehyde occurs spontaneously, with resultant formation of an alicyclic al kaloid (Lauwers el al. 1975; Meller el al., 1975 Rosengarten et al. 1975). The reation of monoamines with formaldehyde (the Picke spengle condensation) is a wellestablished process.

The reaction products with catecholamines are derivatives of $1,2,3,4$-tetahydroisoquimolines, and

Received September 15, 1980; revised July 17.1981; accepled August 20, 1981

Address correspondence and reprint requests to M. I. I with indolamines of $1,2,3,4$-tetrahydro- $\beta$-catbolines.

The physiological and pathological significance of the formaldehyde-derived monoamine alkaloids is, at present, being studied.

Rommelspacher et al. (1979) demonstrated the existence of 6 -hydroxytetrahydro- $\beta$-carboline, the alkaloid from serotonin and formaldehyde, both in man and rat. The alkaloid from tryptamine and formaldehyde $(1,2,3,4$-tetrahydro- $\beta$-carboline) has been identified $i n$ vivo in rat bain by Barker el al. (1979). Folate compounds administered exoge. nously are known to cause convulsive activity (Obbens and Hommes, 1973; Hommes el al., 1979). The monoamine derivatives 4-methoxydopamine and $N$-methyldopaminc, and 1,2,3,4-tetrahydrodimethyl- $\beta$-carboline have also been shown to cause convulsions in the rat, whereas the alkaloid of dopamine exhibits anticonvulsant activity (Hollinger and Hommes, unpublished). Experiments have been carried out, therefore, to determine the effects of these substances on reductase activity, on the

Jansen, Radboud University Hospital, Laboratory of Neurology. Nijmegen, The Netherlands.

thowevion ased: 'THF, Tetrahydrofolic acid 
assumption that the convulsive behaviour induced by folate is dependent upon the formation of alkaloids as a result of reductase activity.

\section{MATERIALS AND METHODS}

5.1"Clmethyltetrahydrofolic acid batiom salt, specilic activity $57 \mathrm{mCi} / \mathrm{mmol}$, was purchased from Radiochemical Centre, Amersham, England, folic acid, dihydrofolic acid, tetrahydrofolic acid, methotrexate, pyrimethamine, sodium glutamate, and $N$-para-aminobenzoyl-1 glutamic acid were purchased from Sigma Chemical (o. 4Methoxydopamine HO, 4-methoxydopamine derivative, epinine, epinine derivative, and 1,2,3,4-tetrahydro-2,9. dimethyl-B-carboline were gifts from P. Laduron, Janssen Pharmaceutica, Beerse, Belgium.

\section{Preparation of rat brain homogenates}

Wistar rats of $160 \cdots 200 \mathrm{~g}$ body weight were killed by decapitation. Their brains were rapidly removed and washed in $0.25 \mathrm{M}$-cold sucrose. The complete brain was homogenized for $1 \mathrm{~min}$ in $10 \mathrm{vol}$. of $0.25 \mathrm{M}$-cold sucrose with a Potter-Elvejhem homogenizer. The suspension was centrifuged for $20 \mathrm{~min}$ at $600 \mathrm{~g}$ to remove cell debris. The supernatant was stored at $-20^{\circ} \mathrm{C}$ until required for enzyme assays.

\section{Enzyme assays in rat brain homogenates}

The 5,10-methylenetetrahydrofolate reductase was eslimated in the reverse direction. We did not use an electron acceptor in the incubation mixture becaltse we used crude enzyme preparations. Crude homogenates contained oxidizing substances, such as FAD, sufficient that addition of such electron acceptors did not further stimu. late the enzyme activity. Only purified enzyme demonstrated a requirement for oxidizing substances in the enzyme assay (Stebbins et al., 1976).

The method we used was based on that of Laduron et al. (1975) with 4-methoxydopamine as the formaldehyde-

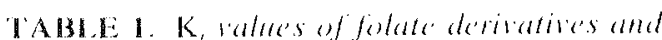

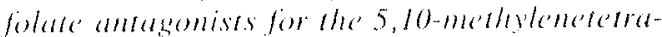
hydrofolate reductase

\begin{tabular}{|c|c|}
\hline Substance & $\begin{array}{l}50 \% \text { inhibition } \\
\text { concentration } \\
\text { (moles/liter) }\end{array}$ \\
\hline Dihydrofolic acid & $7.0 \times 10^{5}$ \\
\hline Folic acid & $3.5 \times 10^{4}$ \\
\hline Tetrabydrofolic acid & $\because 1.0 \times 10^{3}$ \\
\hline Metholiexate & $1.7 \times 10^{5}$ \\
\hline Pyrinethamine & $3.7 \times 101$ \\
\hline S-adenosyl-1 -methionine & $1.8 \times 10^{4}$ \\
\hline N-p-aminobenzoyl-t glutamic acid & No inhibition \\
\hline Sodium glutamate & No inhibition \\
\hline
\end{tabular}

Each value represents the incubation concentration (moles/liter) of inhibito necessary to produce a $50 \%$ inhibition of enzyme activity with $5-1^{16} \mathrm{C}$ methyltetrahydrofolic acid (1.74 nmol/liter) as methyl donor and 4-methoxydopamine as the formaldehyde-binding substance in rat brain homogenates.

binding substance. The incubation mixture contained 100 $\mu 10.5$ M-sodium phosphate buffer, $\mathrm{pH} \mathrm{6.4,150 \mu l}$ glass-distilled water or $100 \mu \mathrm{l}$ of various concentrations of folate derivatives of monoamine derivatives, and $50 \mu \mathrm{l}$ glass-distilled water, $100 \mu / 4$-methoxydopamine $0.1 \mathrm{M}, 50$ 4 . $51^{1.4} \mathrm{C}$ methyletrahydrofolic acid $(10.0 \mu \mathrm{Ci})$, and 100 $\mu$ l enzyme preparation. The blank was prepared without enzyme or with boiled enzyme. After incubation for $2 \mathrm{~h}$ in a water bath at $37^{\circ} \mathrm{C}$, the reaction was stopped by adding $1.0 \mathrm{ml}$ of a $0.5 \mathrm{M}$ sodium borate buffer $\mathrm{pH} 10.0$. The reaction products were extracted in $10.0 \mathrm{ml}$ of a $10 \mathrm{l}$ uene- isoanyl alcohol $2: 3$ mixture from the aqueous phase, previously saturated with $1 \mathrm{~g}$ sodium chloride. Afler mixing on a Vortex mixer for I min, the tubes were centrifuged for $15 \mathrm{~min}$ at $1545 \mathrm{~g}$. Four milliliters of the organic phase were added to a vial with $10.0 \mathrm{ml}$ lnstagel

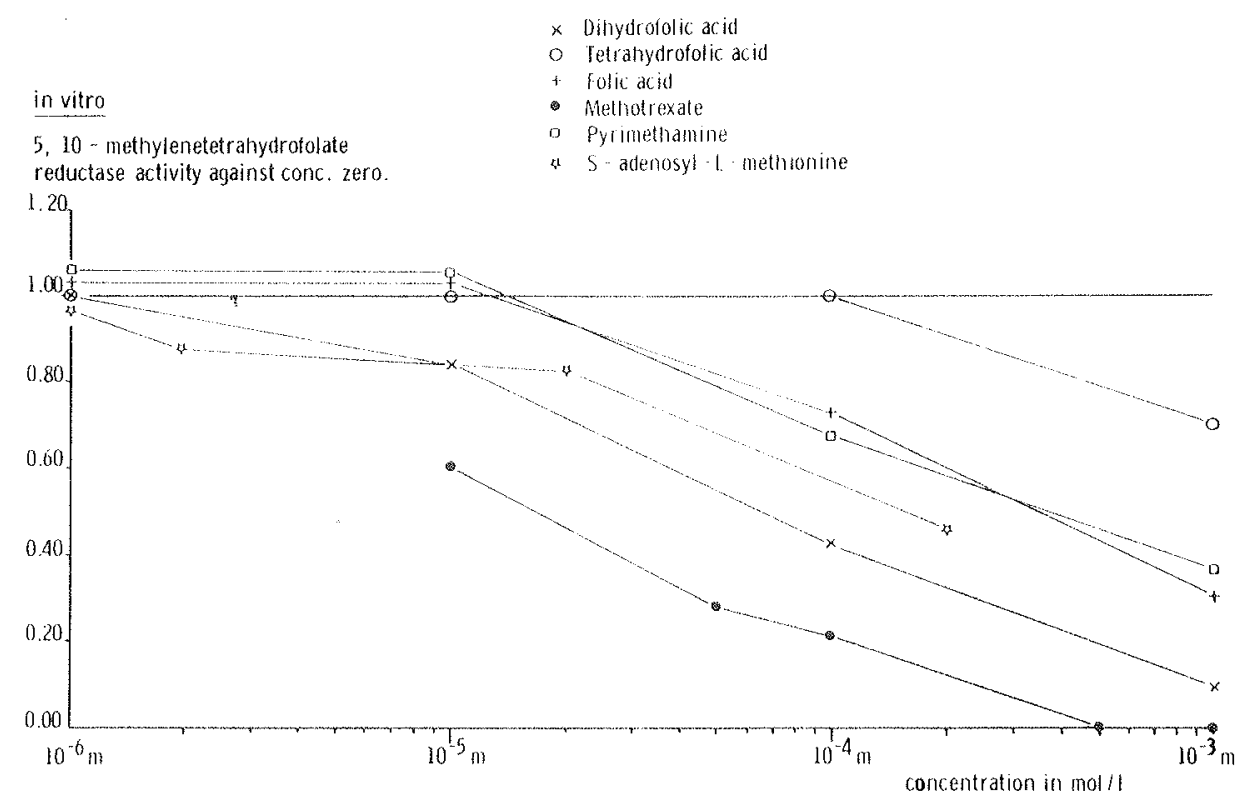

FIG. 1. Inhibition of the 5,10-methylenetetrahydrotolate reductase activity by various concentrations of folate derivatives and folate antagonists in rat brain homogenates in vitro. Reductase activity was measured with 4-methoxydopamine as the formaldehyde-binding substance. 
and the radioativity was measured with a liquid scintillat lion counter. The enzyme activity was expressed in nanomoles "C products per hour per gram lisste

Michaelis -.. Menten kinetics

Whenever kinetic propertics similat lo Michates Menten kinetics were obtaned, the parameters $K_{\text {in }}$ and $V_{\text {mil }}$ were defermined by means of the linewcaver Butk transformation (Lineweaver and Butk, 1934).

\section{RESULTS}

Kinetic properties of

5 , lowethyleneterahydrofolate reductase of rat tissue

The values for $K_{\mathrm{m}}(1.45 \pm 0.25 \mu \mathrm{M})$ and $V_{\mathrm{max}}(7.43$ $\pm 0.33 \mathrm{nmol} / \mathrm{h} / \mathrm{g}$ tissue, mean $\pm \mathrm{S} . \mathrm{D}$.) were determined by measuring the reaction velocities at different concentrations of $5-1^{1 .} \mathrm{C}$ methylterahydrofolic acid with crude enzyme preparations from rat brain. We have been unable to obtain from the literature $K_{m}$ and $V_{\text {max }}$ values for the 5,10-methylenetetrahydrofolate reductase activity of crude rat brain homogenates.

Inhibition of the 5,10 -methylenetei rahydrofolate reductase by folate derivatives and folate antagonists in vitro

The following substances were tested: folic acid, dihydrofolic acid, tetrahydrofolic acid, methotrexate, pyrimethamine, $N$-para-aminobenzoyl-1.glutamic acid, sodium-glutamate, and $S$-adenosylL-methionine. The results are presented in Table 1 and Fig. 1. For the folate monogluamates and folate antagonists an inhibition of the 5,10 methylenetetrahydrofolate reductase could be demonstrated on brain, which was most pronounced in the case of dihydrofolic acid and methotrexate. S-adenosyl-r-methionine was also shown to inhibit the enzyme activity. For sodium glutamate, which is epileplogenic only in high doses, and $N$-para-aminobenzoyl-L-glutamic acid, a constituent part of the folate molecule, no inhibition was shown. Using the lineweaver-Buk transtormation, dihydrofolic acid was found to show competitive inhibitory aclivity on the enzyme (Fig. 2).

Influence of monoamine derivatives on brain 5,10-methylenetetrahydrofolate reductase activity in vitro

Different effects on the 5,10 -methylencterahy. drofolate reductase activiry were observed with the cyclized monoamine derivatives (Table 2). The do. pamine derivative was shown to increase the enzyme activity whereas the epinine derivative and the $\beta$-carboline derivative had inhibitory effects. Epinine had no effect.

\section{DISCUSSION}

Cellular folates are present mostly as their polyglutamate derivatives. In this form they have

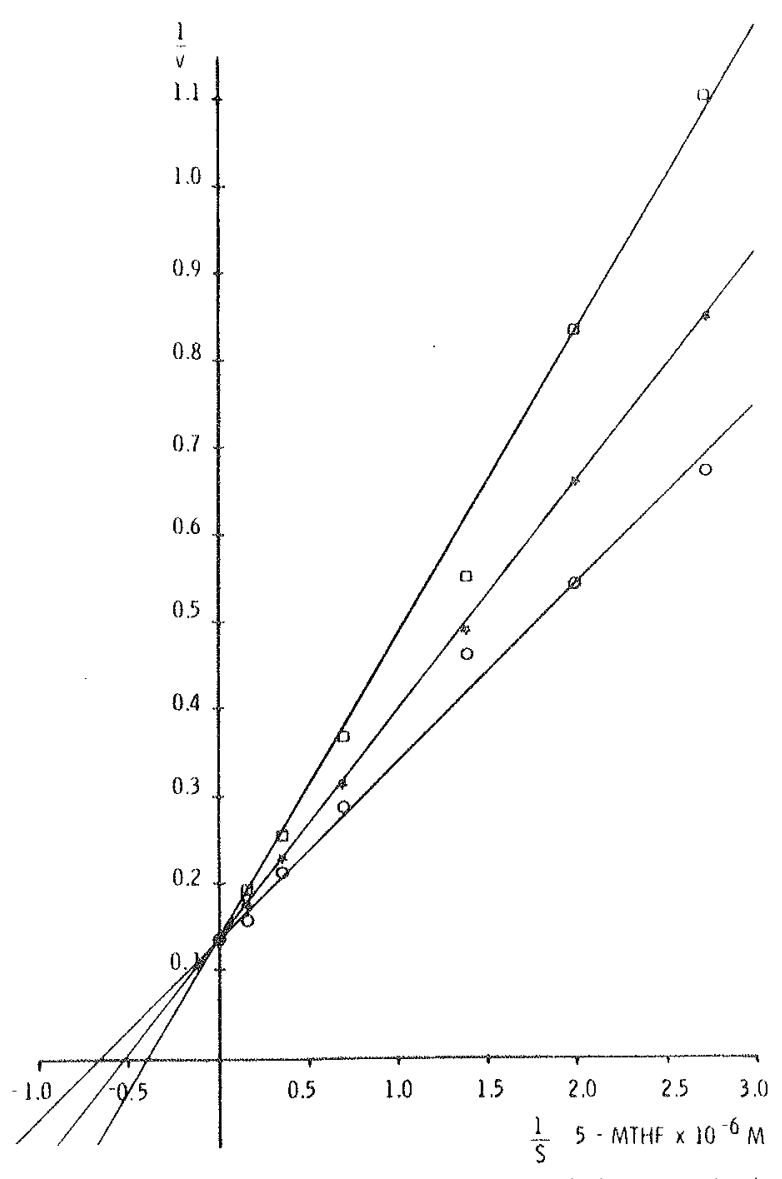

Fia. 2. Lineweaver - Burk plots for 5,10-methylenetetrahydrofolate reductase activity assayed at $\mathrm{pH} 6.4$ with different concentrations of dihydrofolic acid. Each point represents the mean value obtained from duplicate determinations upon a single enzyme source prepared from pooled brains of eight rats. -. - w whout dihydrofolic acid: $K_{m} 1.38$ $\mu \mathrm{m} ; V_{\text {max }} 7.30 \mathrm{nmol} / \mathrm{h} \cdot \mathrm{g}$ tissue. - $^{*}$, dihydrofolic acid $1 \times 10^{\mathrm{s}} \mathrm{M}: K_{\mathrm{m}}+.87 \mu \mathrm{M} ; V_{\max } 7.30 \mathrm{nmol} / \mathrm{h} \cdot \mathrm{g}$ tissue. ............ dihydrofolic acid $2 \times 10^{-5} \mathrm{M}: K_{\mathrm{m}} 3.11 \mu \mathrm{M} ; V_{\max } 7.30 \mathrm{nmol} / \mathrm{h} \cdot \mathrm{g}$ tissue.

been shown to be better substrates (lower $K_{\text {m }}$ ) than monogluamates for folate-dependent enzymes, and may function as natural substrates and as regulators of folate metabolising enzymes (Coward et al. 1974: Cheng el al. 1975). We have performed our studies on the inhibition of 5,10 -methylenetetrahydrofolate reductase, however, with folate monoglutamates, because polyglutamates were not available. The inhibition by dihydrofolic acid was found to be competitive with respect to 5-methyltetrahydrofolic acid, in agreement with the observations of Matthews and Haywood (1979), who used purified reductase from pig liver. The more pronounced inhibition by dihydrofolic acid than that caused by folic acid or tetrahydrofolic acid is probably due to the formation of an intermediate product, an $N^{5}$-methyldihydrofolate derivative, in the enzyme reaction (Matthews and Haywood 1979).

The assumption that folate compounds exert their 


\begin{tabular}{|c|c|c|}
\hline Substance & Concentlation & $\begin{array}{l}\text { Linzyme aclivity } \\
\text { as percentage } \\
\text { of the control }\end{array}$ \\
\hline \multirow[t]{3}{*}{ 4-Methoxydopamine derivative" } & $1 \times 10^{\prime} \mathrm{M}_{1}$ & 100 \\
\hline & $1 \times 10^{1 /} \mathrm{M}$ & 186 \\
\hline & $1 \times 101 \mathrm{M}$ & 116 \\
\hline \multirow[t]{3}{*}{ Dopanine derivative" } & $1.72 \times 10^{*} \mathrm{M}$ & 204 \\
\hline & $1.72 \times 10^{4} \mathrm{M}$ & 120 \\
\hline & $1.72 \times 10 \times \mathrm{M}$ & 105 \\
\hline Epinine & $1.61 \times 107 \mathrm{M}$ & 100 \\
\hline \multirow[t]{3}{*}{ Epiane derivalive" } & $1.53 \times 10^{3} \mathrm{M}$ & 11 \\
\hline & $1.53 \times 10 \times \mathrm{M}$ & 47 \\
\hline & $1.53 \times 10 \times \mathrm{M}$ & 92 \\
\hline \multirow[t]{3}{*}{$\beta \cdot$ Carboline derivaltive } & $1.94 \times 10^{3} \mathrm{M}$ & 15 \\
\hline & $1.94 \times 10^{1} \mathrm{M}$ & 27 \\
\hline & $1.94 \times 10: \mathrm{M}$ & 76 \\
\hline
\end{tabular}

Inhibitory and stimulatory effects of monoamine derivalives on the 5, 10-methylenetetrahydrofolate reductase activity from a single enzyme source prepared from pooled rat brains. Reductase activity was measured with 4-methoxydopamine as the formaldehyde-binding substance.

" $1,2,3,4$-Tetrahydro-7-methoxy-6-isoquinolinol.

" $1,2,3,4$ - Tetrahydro-6,7 isoquinolinediol

"4-[-2-(Methylamino)ethylpyrocatechol.

"1,2,3,4-Tetrahydro-2-methyl-6,7-isoquinolinediol.

" 1,2,3,4-Tetrahydro-2,9-dimethyl- $\beta$-carboline.

convulsant effect by means of stimulation of monoamine alkaloid formation is not confirmed by our results.

The various monoamine derivatives have different effects on the 5,10methylenetetrahydrofolate reductase activity. The dopamine derivative, which is anticonvulsive, stimulates the reductase activity. The epinine derivative and the $\beta$-carboline deriva tive, which were convulsive, inhibit the enzyme acrivity.

These results are the contrary of what we had expected. We had expected that the dopamine derivative, which is anticonvulsive, should inhibit the reductase activity. The epinine derivative and the $\beta$-carboline derivative, being convulsant, should stimulate the reductase activity.

It remains uncertain if the monoamine alkaloids demonstrated in brain tissue (Barker et al., 1979; Rommelspacher et al., 1979), and in human plasma and platelets (Kari et al., 1980) are produced by means of the reductase, which would require the reductase to act in the reverse of its normat physio. logical direction.

Kutzbach and Stokstad (1971) calculated that the enzymatic reduction of 5,10 -methylenetetrahydro.. folate to 5-methylletrahydrofolate has a $K_{0}=10$ at pH 7-thus, under normal physiological conditions, the rate of the reverse reaction is less than $1 \%$ of that of the forward one.

However, the possibility remains that in vivo monoamine alkaloid formation can lake place during the reduction of 5,10-methylenetetrahydrofolate to 5-methyltetrahydrofolate in which an inter. mediate product, the $N^{5}$-methyldihydrofolate, is formed (Matthews and Haywood, 1979). We suggest that from this product the enzyme could transfer a one carbon unit (in the form of formal. dehyde) to monoamines.

\section{REFERENCES}

Banker S. A. Harrison H. H. Brown G. B., and Christian S. I (1979) Gas chromatographic mass/spectrometric evidence for the identification of $1,2,3,4$-temahydro- $\beta$-carboline as an in vivo comstituent of rat brain. Biochem. Biophys. Res. (c)mmmin. 87, 146-154.

(heng W. W. Shate B., and Stokstad E. L. R. (1975) Penta glutamate derivatives of folate as substrate for rat liver tet rahydropteroylglutamate methyltransferase and 5,10 methylenetelahydrofolate reductase. Can. J. Biochem. 53, $1020-1027$.

Coward J. K., Parameswaran K. N., Cashmore A. R., and Bertino J.R. (1974) 7,8-Dihydropteroyl oligo- $\gamma$-L-glutamates: Synthesis and kinetic studies with purified dihydrofolate reduclase from mammalian sources. Biochemistry 13 , $3899 \cdots 3903$.

Donaldson K.O. and Keresztesy J.C. (1961) Further evidence on the nature of prefolic A. Biochem. Biophys. Res. (i)mllmII, 5, $289 \cdots 292$.

Hommes O. R., Hollinger J. L., Jansen M. J. T., Schoofs M., Van de Wiel Th., and Kok J.C.N. (1979) Convulsant properties of folate compounds: Some considerations and speculations; in Folic Acid in Nearology, Psychiatry and Intrinal Medicine (Botez M. 1. and Reynolds E. H., eds), pp. $285 \cdots 316$. Raven Press, New York.

Kari 1., Peura P., and Airaksinen M. (1980) Quantitative gas chromatographic mass spectrometric determination of $1,2,3,4$-telahydro- $\beta$-carboline in human plasma and platelets. Biomed. Mass. Speremom. 7, 549-552

Kulzbach C. and Stokstad E. L. R. (1971) Mammalian methyl- 
enetetahydrololate reductatse. Patial purifiation, prop. erties and inhibiton by sidenosylmethionine. Biodem. Biophys. Aita 250, 459 477 .

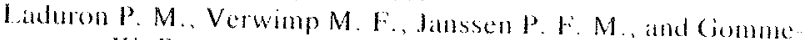
ren $W$ R. (1975) Tisste fractionation in rat bant kidncy and liver. I. Intacellulat localization of a 5 medhylledar hydrotolic acid requiring enzyme. Riochimie foldrait do Timle $57,253 \cdots 260$.

Latuwers W. Leysen J., Verhoeven H., and Ladaton P. (1975) ldentifiation of alkaloids; the condenation products of biogenic amines with formatdehyde, enzymatically formed from 5 methyletrahydrofolic acid. Biomed. Mass. Sper trum. 2, $15 \cdots 22$.

Lineweaver H. and Burk D. (1934) The determination of entyme dissociation constants. J. A/l. Chem. Ses . 56,658\%666

Mathews R. G. and Haywood B. I. (1979) Inhibition of pig live methylenetetrathydrofolate reductase by dihydrofolate Some mechanistic and regulatory implications. Bios hemistry $18,4845 \cdots 4851$.

Meller E., Rosengaten H., Friedhoff A. I., Sicbbins R. D), and Silber R. (1975) 5-Methyltetahydrofolic acid is not a methyl donor for biogenic amines: Lnzymatic formation of for malutehyde. Sicher 187, 171-173

Gblems L. A. M. T. and Hommes O. R. (1973) The epileptogenio effect of folate derivatives in the rat. I. Neturd. Sil. 20 , $223-229$

Ronmelspather H., Honecker H., Babey M., and Meinke: B (1979) 6-Hydroxy-tetrabydronorhatmane (6)hydroxy.

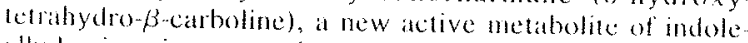

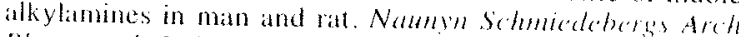
Pharmarol. $310,35 \cdots 43$.

Rosengarten H. Meller L, and Friedhold A. J. 1975) Syothesis of telahydro-s-carbolines from indoleamines viat enzymatic fomation of formaldehyde from 5-methyle tabydiofolic acid. Bionhim. Phamatol. 24, 1759 1762

Stcbbins R. D. Meller E., Rosengarten H., riedholf A. I., and Silber $A$. (1976) Identification of $N^{\circ}, N^{\prime \prime}$ methylene tenahydrofolate reductase as the enzyme involved in the 5-methyltetahydotolatedependent formation of at $\beta$. carboline derivative of 5 -hydroxy-aryptamine in human platelets. Arch. Biochem. Biophys. 173, 673-679. 